\title{
State-Level Economic Costs of Opioid Use Disorder and Fatal Opioid Overdose — United States, 2017
}

\author{
Feijun Luo, $\mathrm{PhD}^{1}$; Mengyao Li, $\mathrm{PhD}^{1}$; Curtis Florence, $\mathrm{PhD}^{1}$
}

Approximately 47,000 persons in the United States died from an opioid-involved overdose in 2018 (1), and 2.0 million persons met the diagnostic criteria for an opioid use disorder in 2017 (2). The economic cost of the U.S. opioid epidemic in 2017 was estimated at $\$ 1,021$ billion, including cost of opioid use disorder estimated at $\$ 471$ billion and cost of fatal opioid overdose estimated at $\$ 550$ billion (3). CDC used nationallevel cost estimates to estimate the state-level economic cost of opioid use disorder and fatal opioid overdose during 2017. Cases and costs of state-level opioid use disorder and fatal opioid overdose and per capita costs were calculated for each of the 38 states and the District of Columbia (DC) that met drug specificity requirements for mortality data (4). Combined costs of opioid use disorder and fatal opioid overdose (combined costs) varied substantially, ranging from $\$ 985$ million in Wyoming to \$72,583 million in Ohio. Per capita combined costs also varied considerably, ranging from $\$ 1,204$ in Hawaii to $\$ 7,247$ in West Virginia. States with high per capita combined costs were mainly in two regions: the Ohio Valley and New England. Federal and state public health agencies can use these data to help guide decisions regarding research, prevention and response activities, and resource allocation.

Estimated case counts of state-level opioid use disorder were extracted from the National Survey on Drug Use and Health (NSDUH) 2-Year Restricted-Use Data Analysis System (2016-2017) provided by the Substance Abuse and Mental Health Services Administration (5). NSDUH is a nationally representative sample of the U.S. civilian noninstitutionalized population aged $\geq 12$ years. Cases of opioid use disorder were identified by using questions on opioid abuse or dependence during the past year.* Case counts of state-level fatal opioid

\footnotetext{
* NSDUH classified respondents as having opioid use disorder during the past year if they had a heroin use disorder (dependence or abuse), pain reliever use disorder (dependence or abuse), or both during the past year.
}

overdose and population estimates in 2017 were extracted from CDC's WONDER database (6). Cases of fatal opioid overdose were identified using International Classification of Diseases, Tenth Revision underlying cause-of-death codes X40-X44, X60-X64, X85, and Y10-Y14 and then multiple causes-ofdeath codes T40.0-T40.4 and T40.6. ${ }^{\dagger}$ This report is limited to $\mathrm{DC}$ and the 38 states that met the requirement that at least one specific drug is named on the death certificate (4). ${ }^{\dagger}$ Cases of fatal opioid overdose include all opioid-related overdose deaths
regardless of intent (intentional, unintentional, homicide, or undetermined).
INSIDE
547 Progress in Immunization Safety Monitoring - Worldwide, 2010-2019
552 Update: COVID-19 Pandemic-Associated Changes in Emergency Department Visits - United States, December 2020-January 2021
557 Factors Associated with Participation in Elementary School-Based SARS-CoV-2 Testing - Salt Lake County, Utah, December 2020-January 2021
560 Trends in Racial and Ethnic Disparities in COVID-19 Hospitalizations, by Region - United States, March-December 2020
566 Emergency Department Visits for COVID-19 by Race and Ethnicity - 13 States, October-December 2020
570 Notes from the Field: Update on Excess Deaths Associated with the COVID-19 Pandemic - United States, January 26, 2020-February 27, 2021
573 COVID-19 Stats
574 QuickStats

Continuing Education examination available at https://www.cdc.gov/mmwr/mmwr_continuingEducation.html

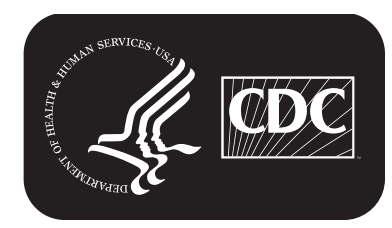

U.S. Department of Health and Human Services Centers for Disease Control and Prevention 
Cost per case of opioid use disorder $(\$ 221,219)$ was derived by dividing the total U.S. cost of opioid use disorder $(\$ 470,975$ million) during 2017 by the number of opioid use disorder cases the same year (2.129 million) (3). Cost per case of fatal opioid overdose ( $\$ 11.548$ million) was derived by dividing the total cost of fatal opioid overdose (\$549,691 million) by the number of fatal opioid overdose cases $(47,600)(3)$. State-level cost of opioid use disorder was calculated by multiplying the U.S. cost of opioid use disorder per case by the number of cases of opioid use disorder in each state. State-level cost of fatal opioid overdose was calculated by multiplying the U.S. cost of fatal opioid overdose per death by the number of deaths in each state. To facilitate comparison across states, CDC divided state-level combined costs of opioid use disorder and fatal opioid overdose by state population to generate per capita costs. The 38 states and DC were ranked by per capita combined costs. Cost components of opioid use disorder and fatal opioid overdose include the costs of health care, substance use treatment, criminal justice, lost productivity, reduced quality of life, and the value of statistical life lost. These components were calculated by multiplying the number of state cases of opioid use disorder or fatal opioid overdose by national cost estimates per case for each component (3). ${ }^{\S}$

\footnotetext{
$\$$ Cost estimates per case for components of opioid use disorder based on the value of a statistical life were as follows: health care, $\$ 14,705$; substance use treatment, $\$ 1,660$; criminal justice, $\$ 6,961$; lost productivity, $\$ 14,707$; and reduced quality of life, $\$ 183,186$. Cost estimates per case for components of fatal opioid overdose were as follows: health care, $\$ 5,462$; lost productivity, $\$ 1.443$ million; and value of statistical life, $\$ 10.1$ million.
}

Cases of opioid use disorder and fatal opioid overdose varied substantially among states, and the combined costs ranged from $\$ 985$ million in Wyoming to $\$ 72,583$ million in Ohio (Table 1). Per capita combined costs also varied widely among states, ranging from $\$ 1,204$ in Hawaii to $\$ 7,247$ in West Virginia. The state-level per capita combined costs exhibited geographic patterns (Figure); states with high per capita combined costs were located mainly in the Ohio Valley and New England. Three adjacent states in the Ohio Valley (West Virginia, Ohio, and Kentucky) had the first, second, and fourth highest per capita combined costs $(\$ 7,247, \$ 6,226$, and $\$ 5,491$, respectively). Per capita costs of fatal opioid overdose were highest in West Virginia $(\$ 5,298)$ and Ohio $(\$ 4,252)$. Per capita combined costs in four neighboring New England states were among the eight highest: New Hampshire (third highest, \$5,953), Massachusetts (fifth highest, \$5,381), Maine (sixth highest, \$5,099), and Connecticut (eighth highest, $\$ 4,800$ ).

States with lower per capita combined costs were mainly in western regions: California, Hawaii, and Wyoming in the West; Minnesota in the Midwest; and Texas in the Southwest. Combined per capita costs were lowest in Hawaii $(\$ 1,204)$ and Minnesota $(\$ 1,509)$. Per capita cost of fatal opioid overdose was the lowest in Hawaii (\$429), and per capita cost of opioid use disorder was the lowest in Minnesota (\$635). The two most populous states (California and Texas) and the least populous state (Wyoming) were among the states with the lowest per capita combined costs: California, third lowest

The MMWR series of publications is published by the Center for Surveillance, Epidemiology, and Laboratory Services, Centers for Disease Control and Prevention (CDC), U.S. Department of Health and Human Services, Atlanta, GA 30329-4027.

Suggested citation: [Author names; first three, then et al., if more than six.] [Report title]. MMWR Morb Mortal Wkly Rep 2021;70:[inclusive page numbers].

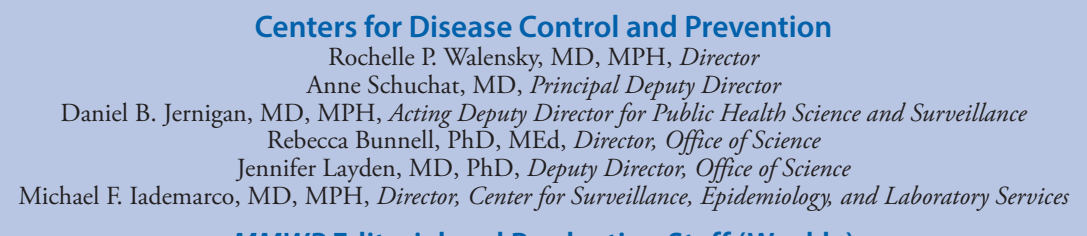

MMWR Editorial and Production Staff (Weekly)

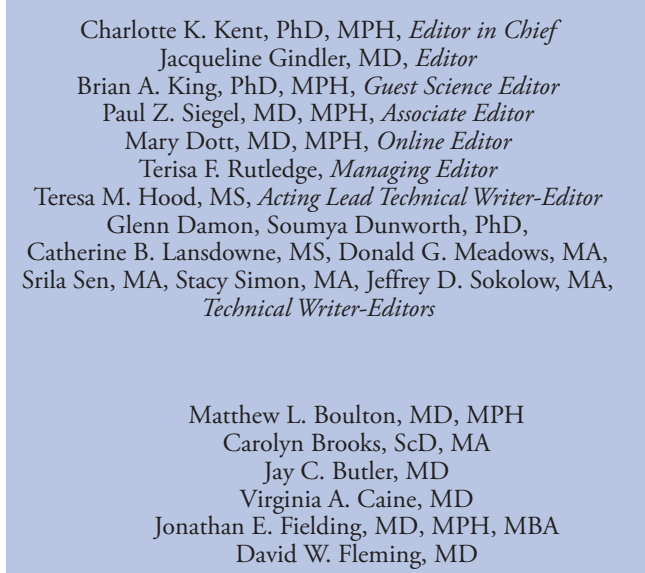

Charlotte K. Kent, PhD, MPH, Editor in Chief Jacqueline Gindler, MD, Editor ul Z. Siegel, MD, MPH, Associate Edito Mary Dott, MD, MPH, Online Editor Terisa F. Rutledge, Managing Editor Glenn Damon, Soumya Dunworth, PhD, Catherine B. Lansdowne, MS, Donald G. Meadows, MA, tacy Simon, MA, Jeffrey D. Sokolow, MA

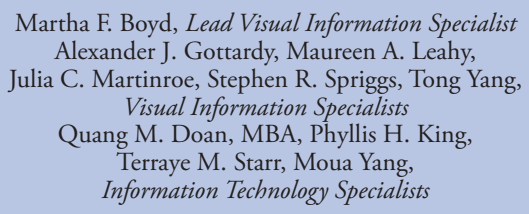
Visual Information Specialists

Quang M. Doan, MBA, Phyllis H. King, Terraye M. Starr, Moua Yang, Information Technology Specialists

Ian Branam, MA, Acting Lead Health Communication Specialist Shelton Bartley, MPH,

Lowery Johnson, Amanda Ray, Jacqueline N. Sanchez, MS, Health Communication Specialists Will Yang, MA, Visual Information Specialist 
TABLE 1. Case counts and costs of opioid use disorder and fatal opioid overdose and per capita cost, by jurisdiction — 38 states and the District of Columbia, $2017 *$

\begin{tabular}{|c|c|c|c|c|c|c|c|c|}
\hline Jurisdiction $^{\dagger}$ & $\begin{array}{l}\text { Estimated } \\
\text { case count of } \\
\text { opioid use } \\
\text { disorder }\end{array}$ & $\begin{array}{l}\text { Case count } \\
\text { of fatal } \\
\text { opioid } \\
\text { overdose }\end{array}$ & $\begin{array}{c}\text { Cost of } \\
\text { opioid use } \\
\text { disorder, } \\
\$ \text { (millions) }\end{array}$ & $\begin{array}{c}\text { Cost of } \\
\text { fatal opioid } \\
\text { overdose, } \\
\$ \text { (millions) }\end{array}$ & $\begin{array}{l}\text { Combined } \\
\text { cost of } \\
\text { opioid use } \\
\text { disorder and } \\
\text { fatal opioid } \\
\text { overdose, } \\
\text { \$ (millions) }\end{array}$ & $\begin{array}{l}\text { Per capita cost of } \\
\text { opioid use } \\
\text { disorder, } \$\end{array}$ & $\begin{array}{c}\text { Per capita } \\
\text { cost of } \\
\text { fatal opioid } \\
\text { overdose, \$ }\end{array}$ & $\begin{array}{l}\text { Per capita } \\
\text { combined } \\
\text { cost of } \\
\text { opioid use } \\
\text { disorder and } \\
\text { fatal opioid } \\
\text { overdose, \$ }\end{array}$ \\
\hline Hawaii & 5,000 & 53 & $1,106.1$ & 612.1 & $1,718.1$ & 775 & 429 & 1,204 \\
\hline Minnesota & 16,000 & 422 & $3,539.5$ & $4,873.3$ & $8,412.8$ & 635 & 874 & 1,509 \\
\hline California & 165,000 & 2,199 & $36,501.1$ & $25,394.3$ & $61,895.5$ & 923 & 642 & 1,566 \\
\hline Wyoming & 2,000 & 47 & 442.4 & 542.8 & 985.2 & 764 & 937 & 1,701 \\
\hline Texas & 146,000 & 1,458 & $32,298.0$ & $16,837.2$ & $49,135.1$ & 1,141 & 595 & 1,736 \\
\hline lowa & 17,000 & 206 & $3,760.7$ & $2,378.9$ & 6,139.6 & 1,196 & 756 & 1,952 \\
\hline Georgia & 41,000 & 1,014 & $9,070.0$ & $11,709.8$ & $20,779.8$ & 870 & 1,123 & 1,992 \\
\hline Mississippi & 20,000 & 185 & $4,424.4$ & $2,136.4$ & $6,560.8$ & 1,483 & 716 & 2,199 \\
\hline Colorado & 35,000 & 578 & $7,742.7$ & $6,674.8$ & $14,417.5$ & 1,381 & 1,190 & 2,571 \\
\hline Oklahoma & 26,000 & 388 & $5,751.7$ & $4,480.7$ & $10,232.4$ & 1,463 & 1,140 & 2,603 \\
\hline Oregon & 37,000 & 344 & $8,185.1$ & $3,972.6$ & $12,157.7$ & 1,976 & 959 & 2,935 \\
\hline New York & 103,000 & 3,224 & $22,785.5$ & $37,231.2$ & $60,016.7$ & 1,148 & 1,876 & 3,024 \\
\hline Missouri & 34,000 & 952 & $7,521.4$ & $10,993.8$ & $18,515.3$ & 1,230 & 1,798 & 3,029 \\
\hline Arizona & 50,000 & 928 & $11,060.9$ & $10,716.7$ & $21,777.6$ & 1,576 & 1,527 & 3,104 \\
\hline New Mexico & 12,000 & 332 & $2,654.6$ & $3,834.0$ & $6,488.6$ & 1,271 & 1,836 & 3,107 \\
\hline Washington & 68,000 & 742 & $15,042.9$ & $8,568.7$ & $23,611.6$ & 2,031 & 1,157 & 3,188 \\
\hline Wisconsin & 36,000 & 926 & $7,963.9$ & $10,693.6$ & $18,657.4$ & 1,374 & 1,845 & 3,219 \\
\hline Illinois & 73,000 & 2,202 & $16,149.0$ & $25,429.0$ & $41,578.0$ & 1,261 & 1,986 & 3,248 \\
\hline Florida & 140,000 & 3,245 & $30,970.6$ & $37,473.7$ & $68,444.3$ & 1,476 & 1,786 & 3,262 \\
\hline Virginia & 63,000 & 1,241 & $13,936.8$ & $14,331.2$ & $28,268.0$ & 1,645 & 1,692 & 3,337 \\
\hline South Carolina & 37,000 & 749 & $8,185.1$ & $8,649.5$ & $16,834.6$ & 1,629 & 1,722 & 3,351 \\
\hline Alaska & 6,000 & 102 & $1,327.3$ & 1,177.9 & $2,505.2$ & 1,794 & 1,592 & 3,386 \\
\hline Tennessee & 44,000 & 1,269 & $9,733.6$ & $14,654.6$ & $24,388.2$ & 1,449 & 2,182 & 3,631 \\
\hline North Carolina & 76,000 & 1,953 & $16,812.6$ & $22,553.5$ & $39,366.1$ & 1,637 & 2,195 & 3,832 \\
\hline Utah & 30,000 & 456 & 6,636.6 & $5,265.9$ & $11,902.5$ & 2,140 & 1,698 & 3,837 \\
\hline Vermont & 5,000 & 114 & $1,106.1$ & $1,316.5$ & $2,422.6$ & 1,774 & 2,111 & 3,884 \\
\hline Indiana & 56,000 & 1,176 & $12,388.3$ & $13,580.6$ & $25,968.9$ & 1,858 & 2,037 & 3,895 \\
\hline Nevada & 34,000 & 412 & $7,521.4$ & $4,757.8$ & $12,279.3$ & 2,509 & 1,587 & 4,096 \\
\hline Michigan & 81,000 & 2,033 & $17,918.7$ & $23,477.3$ & $41,396.1$ & 1,799 & 2,357 & 4,155 \\
\hline Rhode Island & 6,000 & 277 & $1,327.3$ & $3,198.8$ & $4,526.1$ & 1,253 & 3,019 & 4,271 \\
\hline $\begin{array}{l}\text { District of } \\
\text { Columbia }\end{array}$ & 2,000 & 244 & 442.4 & $2,817.7$ & $3,260.2$ & 638 & 4,060 & 4,698 \\
\hline Connecticut & 28,000 & 955 & $6,194.1$ & $11,028.5$ & $17,222.6$ & 1,726 & 3,074 & 4,800 \\
\hline Maryland & 30,000 & 1,985 & $6,636.6$ & $22,923.0$ & $29,559.6$ & 1,097 & 3,788 & 4,884 \\
\hline Maine & 12,000 & 360 & $2,654.6$ & $4,157.3$ & $6,812.0$ & 1,987 & 3,112 & 5,099 \\
\hline Massachusetts & 67,000 & 1,913 & $14,821.7$ & $22,091.6$ & $36,913.2$ & 2,161 & 3,220 & 5,381 \\
\hline Kentucky & 50,000 & 1,160 & $11,060.9$ & $13,395.8$ & $24,456.8$ & 2,483 & 3,007 & 5,491 \\
\hline New Hampshire & 14,000 & 424 & $3,097.1$ & $4,896.4$ & 7,993.5 & 2,306 & 3,646 & 5,953 \\
\hline Ohio & 104,000 & 4,293 & $23,006.8$ & $49,576.1$ & $72,582.9$ & 1,973 & 4,252 & 6,226 \\
\hline West Virginia & 16,000 & 833 & $3,539.5$ & $9,619.6$ & $13,159.1$ & 1,949 & 5,298 & 7,247 \\
\hline
\end{tabular}

Source: Florence C, Luo F, Rice K. The economic burden of opioid use disorder and fatal opioid overdose in the United States, 2017. Drug Alcohol Depend 2021;218:108350. https://linkinghub.elsevier.com/retrieve/pii/S0376871620305159

* Estimated case counts of opioid use disorder in 2017 were extracted from the National Survey on Drug Use and Health's 2-Year Restricted-Use Data Analysis System (2016-2017); cases of opioid use disorder were identified by using questions on opioid abuse or dependence during the past year; case counts of fatal opioid overdose and population estimates in 2017 were extracted from CDC's WONDER database; cases of fatal opioid overdose were identified using International Classification of Diseases, Tenth Revision codes for the underlying cause-of-death (X40-X44, X60-X64, X85, and Y10-Y14) and then for multiple causes-of-death (T40.0-T40.4 and T40.6).

† Jurisdictions are listed in ascending order of per capita combined cost of opioid use disorder and fatal opioid overdose.

$(\$ 1,566)$, Wyoming, fourth lowest $(\$ 1,701)$ and Texas, fifth lowest $(\$ 1,736)$.

Reduced quality of life was the largest component of the cost of opioid use disorder, and the value of statistical life lost was the largest component of the cost of fatal opioid overdose (Table 2). These two components together accounted for approximately $84 \%$ of combined costs, followed by lost productivity.

\section{Discussion}

The opioid overdose epidemic had a substantial economic impact on the United States during 2017. Individual states differed widely in overall and per capita economic cost. Per capita combined costs of opioid use disorder and fatal opioid overdose were highest in states in the Ohio Valley and New England 
FIGURE. Per capita combined costs* of opioid use disorder and fatal opioid overdose - United States, 2017

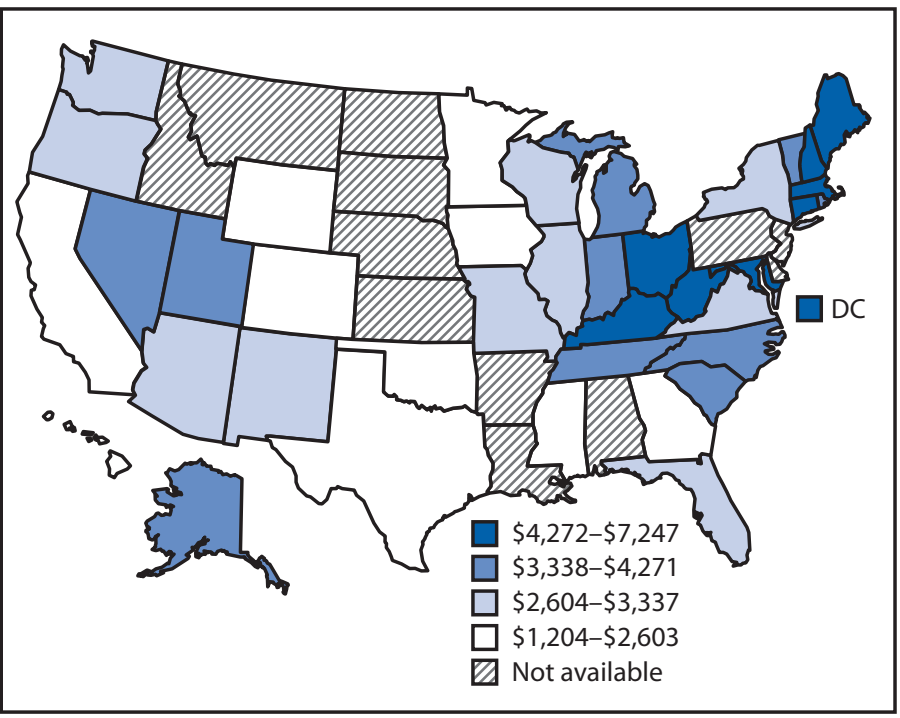

Abbreviation: $\mathrm{DC}=$ District of Columbia.

* Per capita combined costs are combined costs of opioid use disorder and fatal opioid overdose divided by state population and are expressed in 2017 U.S. dollars.

regions. Three states in New England (Connecticut, Maine, and Massachusetts) had high per capita combined costs in 2017. However, previous reports have shown that these states had low per capita lifetime medical and work-loss costs from all fatal injuries (including opioid overdose) in 2014 (7). Further investigation is needed to ascertain why states that have relatively low costs for other types of injuries have relatively high costs related to opioid use disorder and fatal overdose.

Several effective strategies have been identified to improve opioid prescribing consistent with clinical guidelines, treat opioid use disorder, and prevent fatal overdose. Pain clinic laws and combined implementation of mandated provider review of state-run prescription drug monitoring program data have reduced the amounts of opioids prescribed and prescription opioid overdose death rates (8). Treatment with Food and Drug Administration-approved medications (methadone, buprenorphine, or naltrexone) is the most effective form of treatment for opioid use disorder (9). Overdose education and nasal naloxone distribution programs reduced opioid overdose mortality rates in Massachusetts (10).

The findings in this report are subject to at least four limitations. First, this study is limited to the 38 states and DC that met drug specificity requirements for mortality data, so the rankings of combined costs and per capita costs do not apply to all 50 states. Second, the cost of opioid use disorder was measured for a single year rather than a lifetime, even though opioid use disorder might have a long-lasting effect on a person's life. Third, the estimated case counts of opioid use

\section{Summary}

What is already known about this topic?

The U.S. economic cost of opioid use disorder ( $\$ 471$ billion) and fatal opioid overdose ( $\$ 550$ billion) during 2017 totaled $\$ 1,021$ billion.

What is added by this report?

In the 39 jurisdictions studied, combined costs of opioid use disorder and fatal opioid overdose varied from $\$ 985$ million in Wyoming to $\$ 72,583$ million in Ohio. Per capita combined costs varied from $\$ 1,204$ in Hawaii to $\$ 7,247$ in West Virginia. States with high per capita combined costs were located mainly in the Ohio Valley and New England.

What are the implications for public health practice?

Federal and state public health agencies can use these data to help guide decisions regarding research, prevention and response activities, and resource allocation.

disorder likely underrepresent the true prevalence of opioid use disorder because NSDUH does not include persons who are incarcerated or experiencing homelessness, two groups that often have high rates of opioid use disorder. Finally, this study did not directly calculate state costs per case of opioid use disorder and fatal opioid overdose but rather applied the national costs per case of opioid use disorder and fatal opioid overdose to individual states. Population characteristics of opioid use disorder and fatal opioid overdose cases at the state level might differ from those at the national level, potentially biasing state cost estimates.

These estimated costs of opioid use disorder and fatal opioid overdose and their per capita costs at the state level can assist federal and state decision makers in understanding the magnitude of opioid use disorder and fatal opioid overdose in their jurisdictions. Federal and state public health agencies can use these data to help guide decisions regarding research, prevention and response activities, and resource allocation.

Corresponding author: Feijun Luo, hto1@cdc.gov, 770-488-3896.

${ }^{1}$ Division of Injury Prevention, National Center for Injury Prevention and Control, CDC.

All authors have completed and submitted the International Committee of Medical Journal Editors form for disclosure of potential conflicts of interest. No potential conflicts of interest were disclosed.

\section{References}

1. Hedegaard H, Miniño AM, Warner M. Drug overdose deaths in the United States, 1999-2018. NCHS data brief, no 356. Hyattsville, MD: US Department of Health and Human Services, CDC, National Center for Health Statistics; 2020. https://www.cdc.gov/nchs/data/databriefs/ db356-h.pdf

2. Center for Behavioral Health Statistics and Quality. Results from the 2018 National Survey on Drug Use and Health: detailed tables. Rockville, MD: US Department of Health and Human Services, Substance Abuse and Mental Health Services Administration; 2019. https://www.samhsa. gov/data/report/2018-nsduh-detailed-tables 
Morbidity and Mortality Weekly Report

TABLE 2. Cost components of opioid use disorder and fatal opioid overdose, by jurisdiction — 38 states and the District of Columbia, $2017^{*}$

\begin{tabular}{|c|c|c|c|c|c|c|c|c|c|c|}
\hline \multirow[b]{2}{*}{ Jurisdiction $^{\dagger}$} & \multirow[b]{2}{*}{$\begin{array}{l}\text { Estimated } \\
\text { case counts } \\
\text { of opioid use } \\
\text { disorder }\end{array}$} & \multicolumn{5}{|c|}{$\begin{array}{c}\text { Cost components of opioid use disorder, } \\
\$ \text { (millions) }\end{array}$} & \multirow[b]{2}{*}{$\begin{array}{l}\text { Case counts } \\
\text { of fatal } \\
\text { opioid } \\
\text { overdose }\end{array}$} & \multicolumn{3}{|c|}{$\begin{array}{c}\text { Cost components of fatal opioid overdose, } \\
\$ \text { (millions) }\end{array}$} \\
\hline & & $\begin{array}{l}\text { Health } \\
\text { care }\end{array}$ & $\begin{array}{l}\text { Substance } \\
\text { use } \\
\text { treatment }\end{array}$ & $\begin{array}{l}\text { Criminal } \\
\text { justice }\end{array}$ & $\begin{array}{l}\text { Lost } \\
\text { productivity }\end{array}$ & $\begin{array}{l}\text { Reduced } \\
\text { quality } \\
\text { of life }\end{array}$ & & Health care & $\begin{array}{l}\text { Lost } \\
\text { productivity }\end{array}$ & $\begin{array}{c}\text { Value of } \\
\text { statistical life } \\
\text { lost }\end{array}$ \\
\hline Hawaii & 5,000 & 73.5 & 8.3 & 34.8 & 73.5 & 915.9 & 53 & 0.3 & 76.5 & 535.3 \\
\hline Minnesota & 16,000 & 235.3 & 26.6 & 111.4 & 235.3 & $2,931.0$ & 422 & 2.3 & 609.0 & $4,262.0$ \\
\hline California & 165,000 & $2,426.4$ & 273.9 & $1,148.5$ & $2,426.6$ & $30,225.7$ & 2,199 & 12.0 & $3,173.5$ & $22,208.8$ \\
\hline Wyoming & 2,000 & 29.4 & 3.3 & 13.9 & 29.4 & 366.4 & 47 & 0.3 & 67.8 & 474.7 \\
\hline Texas & 146,000 & $2,147.0$ & 242.4 & $1,016.2$ & $2,147.2$ & $26,745.2$ & 1,458 & 8.0 & $2,104.1$ & $14,725.1$ \\
\hline lowa & 17,000 & 250.0 & 28.2 & 118.3 & 250.0 & $3,114.2$ & 206 & 1.1 & 297.3 & $2,080.5$ \\
\hline Georgia & 41,000 & 602.9 & 68.1 & 285.4 & 603.0 & $7,510.6$ & 1,014 & 5.5 & $1,463.4$ & $10,240.9$ \\
\hline Mississippi & 20,000 & 294.1 & 33.2 & 139.2 & 294.1 & $3,663.7$ & 185 & 1.0 & 267.0 & $1,868.4$ \\
\hline Colorado & 35,000 & 514.7 & 58.1 & 243.6 & 514.7 & $6,411.5$ & 578 & 3.2 & 834.1 & $5,837.5$ \\
\hline Oklahoma & 26,000 & 382.3 & 43.2 & 181.0 & 382.4 & $4,762.8$ & 388 & 2.1 & 559.9 & $3,918.6$ \\
\hline Oregon & 37,000 & 544.1 & 61.4 & 257.5 & 544.2 & $6,777.9$ & 344 & 1.9 & 496.4 & $3,474.2$ \\
\hline New York & 103,000 & $1,514.7$ & 171.0 & 716.9 & $1,514.8$ & $18,868.2$ & 3,224 & 17.6 & $4,652.7$ & $32,560.8$ \\
\hline Missouri & 34,000 & 500.0 & 56.4 & 236.7 & 500.0 & $6,228.3$ & 952 & 5.2 & $1,373.9$ & $9,614.7$ \\
\hline Arizona & 50,000 & 735.3 & 83.0 & 348.0 & 735.3 & $9,159.3$ & 928 & 5.1 & $1,339.2$ & $9,372.4$ \\
\hline New Mexico & 12,000 & 176.5 & 19.9 & 83.5 & 176.5 & 2,198.2 & 332 & 1.8 & 479.1 & $3,353.0$ \\
\hline Washington & 68,000 & $1,000.0$ & 112.9 & 473.3 & $1,000.1$ & $12,456.6$ & 742 & 4.1 & $1,070.8$ & $7,493.8$ \\
\hline Wisconsin & 36,000 & 529.4 & 59.8 & 250.6 & 529.4 & 6,594.7 & 926 & 5.1 & $1,336.4$ & $9,352.2$ \\
\hline Illinois & 73,000 & $1,073.5$ & 121.2 & 508.1 & $1,073.6$ & $13,372.6$ & 2,202 & 12.0 & $3,177.8$ & $22,239.1$ \\
\hline Florida & 140,000 & $2,058.8$ & 232.4 & 974.5 & $2,059.0$ & $25,646.0$ & 3,245 & 17.7 & $4,683.0$ & $32,772.9$ \\
\hline Virginia & 63,000 & 926.4 & 104.6 & 438.5 & 926.5 & $11,540.7$ & 1,241 & 6.8 & $1,791.0$ & $12,533.5$ \\
\hline South Carolina & 37,000 & 544.1 & 61.4 & 257.5 & 544.2 & $6,777.9$ & 749 & 4.1 & $1,080.9$ & $7,564.5$ \\
\hline Alaska & 6,000 & 88.2 & 10.0 & 41.8 & 88.2 & $1,099.1$ & 102 & 0.6 & 147.2 & $1,030.2$ \\
\hline Tennessee & 44,000 & 647.0 & 73.0 & 306.3 & 647.1 & $8,060.2$ & 1,269 & 6.9 & $1,831.4$ & $12,816.3$ \\
\hline North Carolina & 76,000 & $1,117.6$ & 126.2 & 529.0 & $1,117.7$ & $13,922.1$ & 1,953 & 10.7 & $2,818.5$ & $19,724.4$ \\
\hline Utah & 30,000 & 441.2 & 49.8 & 208.8 & 441.2 & 5,495.6 & 456 & 2.5 & 658.1 & $4,605.4$ \\
\hline Vermont & 5,000 & 73.5 & 8.3 & 34.8 & 73.5 & 915.9 & 114 & 0.6 & 164.5 & $1,151.3$ \\
\hline Indiana & 56,000 & 823.5 & 93.0 & 389.8 & 823.6 & $10,258.4$ & 1,176 & 6.4 & $1,697.1$ & $11,877.0$ \\
\hline Nevada & 34,000 & 500.0 & 56.4 & 236.7 & 500.0 & $6,228.3$ & 412 & 2.3 & 594.6 & $4,161.0$ \\
\hline Michigan & 81,000 & $1,191.1$ & 134.5 & 563.8 & $1,191.3$ & $14,838.1$ & 2,033 & 11.1 & $2,933.9$ & $20,532.3$ \\
\hline Rhode Island & 6,000 & 88.2 & 10.0 & 41.8 & 88.2 & 1,099.1 & 277 & 1.5 & 399.8 & $2,797.6$ \\
\hline $\begin{array}{l}\text { District of } \\
\text { Columbia }\end{array}$ & 2,000 & 29.4 & 3.3 & 13.9 & 29.4 & 366.4 & 244 & 1.3 & 352.1 & $2,464.3$ \\
\hline Connecticut & 28,000 & 411.8 & 46.5 & 194.9 & 411.8 & $5,129.2$ & 955 & 5.2 & $1,378.2$ & $9,645.0$ \\
\hline Maryland & 30,000 & 441.2 & 49.8 & 208.8 & 441.2 & $5,495.6$ & 1,985 & 10.8 & $2,864.7$ & $20,047.5$ \\
\hline Maine & 12,000 & 176.5 & 19.9 & 83.5 & 176.5 & 2,198.2 & 360 & 2.0 & 519.5 & $3,635.8$ \\
\hline Massachusetts & 67,000 & 985.3 & 111.2 & 466.4 & 985.4 & $12,273.5$ & 1,913 & 10.4 & $2,760.7$ & $19,320.4$ \\
\hline Kentucky & 50,000 & 735.3 & 83.0 & 348.0 & 735.3 & $9,159.3$ & 1,160 & 6.3 & $1,674.1$ & $11,715.4$ \\
\hline New Hampshire & 14,000 & 205.9 & 23.2 & 97.4 & 205.9 & $2,564.6$ & 424 & 2.3 & 611.9 & $4,282.2$ \\
\hline Ohio & 104,000 & $1,529.4$ & 172.6 & 723.9 & $1,529.5$ & $19,051.3$ & 4,293 & 23.4 & $6,195.4$ & $43,357.2$ \\
\hline West Virginia & 16,000 & 235.3 & 26.6 & 111.4 & 235.3 & $2,931.0$ & 833 & 4.6 & $1,202.1$ & $8,412.9$ \\
\hline
\end{tabular}

Source: Florence C, Luo F, Rice K. The economic burden of opioid use disorder and fatal opioid overdose in the United States, 2017. Drug Alcohol Depend 2021;218:108350. https://linkinghub.elsevier.com/retrieve/pii/S0376871620305159

* Estimated case counts of opioid use disorder in 2017 were extracted from the National Survey on Drug Use and Health's 2-Year Restricted-Use Data Analysis System (2016-2017); cases of opioid use disorder were identified by using questions on opioid abuse or dependence during the past year; case counts of fatal opioid overdose and population estimates in 2017 were extracted from CDC's WONDER database; cases of fatal opioid overdose were identified by using International Classification of Diseases, Tenth Revision codes for the underlying cause-of-death (X40-X44, X60-X64, X85, and Y10-Y14) and then for multiple causes-of-death (T40.0-T40.4 and T40.6).

† Jurisdictions are listed in ascending order of per capita combined cost of opioid use disorder and fatal opioid overdose.

3. Florence C, Luo F, Rice K. The economic burden of opioid use disorder and fatal opioid overdose in the United States, 2017. Drug Alcohol Depend 2021;218:108350. PMID:33121867 https://doi.org/10.1016/j. drugalcdep.2020.108350

4. Wilson N, Kariisa M, Seth P, Smith H 4th, Davis NL. Drug and opioidinvolved overdose deaths_-United States, 2017-2018. MMWR Morb Mortal Wkly Rep 2020;69:290-7. PMID:32191688 https://doi. org/10.15585/mmwr.mm6911a4
5. Substance Abuse and Mental Health Services Administration. National survey on drug use and health: 2-year RDAS (2016 to 2017). Rockville, MD: US Department of Health and Human Services, Substance Abuse and Mental Health Services Administration; 2021. https://rdas.samhsa. gov/\#/survey/NSDUH-2016-2017-RD02YR

6. CDC. CDC WONDER: about multiple cause of death, 1999-2019. Atlanta, GA: US Department of Health and Human Services, CDC; 2020. https://wonder.cdc.gov/mcd-icd10.html 
7. Luo F, Florence C. State-level lifetime medical and work-loss costs of fatal injuries-United States, 2014. MMWR Morb Mortal Wkly Rep 2017;66:1-11. PMID:28081055 https://doi.org/10.15585/mmwr. mm6601a1

8. Dowell D, Zhang K, Noonan RK, Hockenberry JM. Mandatory provider review and pain clinic laws reduce the amounts of opioids prescribed and overdose death rates. Health Aff (Millwood) 2016;35:1876-83. PMID:27702962 https://doi.org/10.1377/hlthaff.2016.0448
9. National Academies of Sciences, Engineering, and Medicine. Medications for opioid use disorder save lives. Washington, DC: The National Academies Press; 2019.

10. Walley AY, Xuan Z, Hackman HH, et al. Opioid overdose rates and implementation of overdose education and nasal naloxone distribution in Massachusetts: interrupted time series analysis. BMJ 2013;346:f174. PMID:23372174 https://doi.org/10.1136/bmj.f174 